\title{
The Unsustainable US Health Care System: A Blueprint for Change
}

Jennifer DeVoe, MD, DPbil

Department of Family Medicine, Oregon Health and Science University, Portland

\begin{abstract}
As a family physician, I have become increasingly uncomfortable being associated with the US health care system. While shiny, new buildings go up each day, there is still little movement toward a model that will shore up the crumbling foundation. The current delivery system and financing structures are unsustainable. Inequitable distribution of resources continues, and an increasing number of American families do not have access to adequate care. In this essay, patient stories are woven into a narrative that highlights the magnitude of the problem at multiple levels of the system. My intent is not to compare stories, because we all have patients, friends, and family members who have been affected. The purpose of this essay is to encourage each reader to reflect on his or her own experiences and to present an imperative to lead change.
\end{abstract}

Ann Fam Med 2008;6:263-266. DOI: 10.1370/afm.837.

\section{INTRODUCTION}

$\mathrm{D}$ uring the past few years, my clinical time has shifted more toward helping patients find creative ways to afford their medical care, leaving less time to actually provide primary care services. Although annual health care spending in the United States nears $\$ 7,500$ per person ( $\$ 2.2$ trillion), the current system is eroding —often denying patients basic services. ${ }^{1}$ In this essay, I present short vignettes to illustrate how multiple system components are breaking down. Second, I offer a blueprint for rebuilding the system. Both the vignettes and the blueprint use an analogy of bricks and mortar. In this analogy, the US health care system is portrayed as an enormous building that is supported by several pillars. It envisions all aspects of delivering care as the physical structure held up by pillars that represent crucial financing elements. And, while individual clinics and hospitals have closed their doors as the system crumbles, my analogy of bricks and mortar is intended to go beyond these physical structures. Indeed, this analogy suggests that, as the US health care system threatens to collapse under its own weight, family physicians must be proactive and lead meaningful change.

\section{Unaffordable Health Insurance}

Janice recently came to see me about her bronchitis. Before leaving, she asked me to examine her baby's lungs. Her eyes told me-even before she said the words - that he had no health insurance. At work she is required to pay the total cost of her children's insurance. She has one major problemthe cost of her monthly family premium is more than her net earnings.

Each day more people face Janice's situation. From 1996 to 2003, annual family health insurance premiums increased an average of $11 \%$ while household earnings increased only $3 \%$. If these trends continue, the cost of an average family's premium will surpass their income by the year $2025 .^{2}$

Recent expansions in cost-sharing mechanisms, such as co-payments and high deductibles, have shifted more of the burden onto families and 
slowed the increase in health insurance premiums. These cost containment efforts, however, only postpone the inevitable need to overhaul the employersponsored insurance system. As support from this pillar of health care financing weakens, underinsured working families live in fear of developing a medical problem that could lead to financial ruin. In fact, unaffordable medical expenses contribute to nearly one-half of all personal bankruptcies-mostly among families with health insurance. ${ }^{3}$ Without adequate insurance, people are forced to incur unaffordable health care costs or to gamble on their health, forgoing needed care

\section{Gaps in Coverage}

For Molly's 50-year-old husband, the gamble came at great cost. Shortly after the loss of his job last year, he applied for temporary insurance benefits. During this coverage gap, he developed some troubling symptoms but was afraid to seek care until he received the final approval of his insurance application. If it was something bad, he would not only have to pay out-ofpocket, but he would also acquire a preexisting condition that might make him uninsurable. While waiting, he had a massive heart attack and died. Several weeks later, his widow asked me if her husband's death might have been prevented by having uninterrupted access to his family physician. Together we grappled with the complex question of how our health care system can justify spending more money on new skyscrapers and improved technologies when it failed to provide her husband continuous access to primary health care services that might have saved his life.

\section{Waiting for Medicare}

Health insurance has become a transient phenomenon in this country. Everyone younger than 65 years is at risk of becoming uninsured. It is estimated that 82 million Americans have an insurance coverage gap during a 2-year period. ${ }^{4}$ Many find themselves in situations similar to that faced by Molly's husband ... waiting for coverage. Oftentimes, the long wait ends only when they qualify for Medicare.

I have several uninsured patients anxiously waiting for Medicare.

Laura now lives on a limited budget from her disability benefits after losing her job (and her insurance coverage). I recently called Laura, 55 years old and diabetic, to find out why she had missed an appointment. She told me that she could not visit my office until she receives her Medicare coverage-in 2 years. Her disability income is too much to qualify for Medicaid but not enough to use a COBRA option to purchase her previous employer-sponsored plan. After repeated denials from the private market for temporary coverage, she was told by one insurance representative to "wait for Medicare" and to catch up with health care visits at that time. She finally agreed to see me despite being uninsured. At that visit, I diagnosed gangrene in several toes. Her toes were amputated the next day. She will likely lose her entire foot.

Consumed with day-to-day frustrations about Medicare's complex regulations, I rarely think about the long-term reality: what will happen to patients like Laura if Medicare's pillar collapses under the weight of increasing costs, baby boomers, Medicare Part D, and so on? According to estimates made by the Government Accountability Office (GAO), Medicare is now running a deficit and is projected to become completely insolvent by the year 2026..$^{5,6}$

\section{Turning to the States for Help}

When federal programs such as Medicare cannot provide adequate support, can we turn to the states? State Medicaid insurance plans showed promise with the expansion of coverage to more low-income populations in the 1990s. Medicaid's pillar, however, can be destabilized by an economic downturn, as evidenced by what happened during the recent recession.

In 2003 fiscal constraints nearly derailed the Oregon Health Plan (OHP), an innovative Medicaid program in my home state. ${ }^{7}$ For Peggy, the most fearful aspect of OHP cutbacks was the loss of mental health and chemical dependency benefits. A former heroin addict, Peggy had relied on methadone maintenance programs to stay clean. She was back in the workforce and rebuilding her life. Suddenly, she was facing the abrupt loss of methadone maintenance and could not afford to pay out-of-pocket for the services. I held her hand in my office as she described fears about the loss of her methadone program and her long-time counselor. Three weeks later, I held her hand as she lay dying in the Intensive Care Unit after a heroin overdose.

\section{How About the Safety Net?}

The US health care system cannot rely on tenuous state Medicaid programs even though they are at the top of most state budgets, now directly competing with education for limited dollars. Unlike the federal government, states must balance their budgets and cannot borrow money from the future. State lawmakers hoping to provide more services must also depend on precarious support from the federal government to reauthorize programs like the State Children's Health Insurance Program (SCHIP). So, how about the "safety net"? The United States has a wonderful network of Federally-Qualified Health Centers (FQHCs), started in the 1960 s as neighborhood health centers. 
These safety net clinics are a perfect option for a patient like Stan, who works 60 hours a week at 2 jobs but does not have health insurance. Unfortunately, Stan spent 5 hours attempting to get an urgent appointment at an FQHC before driving 2 hours to see me at a free, charity clinic. For Stan, FQHCs are not a realistic option.

As people lose Medicaid coverage, FQHCs are suddenly finding themselves with thousands more uninsured patients overnight. (Tennessee's Medicaid program, TennCare, had to abruptly drop more than 200,000 patients in $2005 .{ }^{8}$ ) The growing number of uninsured patients, budget cutbacks, and various other financial strains threaten the sustainability of FQHCs and their ability to continue offering accessible services. ${ }^{9,10}$

\section{Disappearing Hospital Emergency Departments} When hearing the stories of Stan, Janice, and others, friends and colleagues have assured me that people without health insurance always have access to the hospital emergency department. Hospitals provide a crucial service to communities and often engender peace of mind for the uninsured. In some communities, however, there is no longer an emergency department - this pillar of last resort has been dismantled. To avoid collapse, many hospitals are expanding lucrative services while closing money-losing programs, such as free clinics and emergency services. Some experts warn that US hospitals could soon resemble US airlines and be forced to severely cut costs, eliminate services, and suffer serious financial instability. ${ }^{11}$ These changes could mean the disappearance of safe havens, leaving no health care options for those unable to pay.

For many communities, saving the hospital requires taking money from other social services, such as education, housing, and environmental protections. This redistribution of social resources leads to a major conundrum about how best to improve the nation's health. According to the World Health Organization, a population's health is strongly affected by social and economic circumstances. So, the redistribution of resources toward more medical care and away from welfare, employment, and education services will actually compromise our nation's health. ${ }^{12}$

\section{THE MAJOR IMPERATIVE-REBUILD THE US HEALTH CARE SYSTEM}

After reaching the conclusion that every major pillar in the US health care system has weakened, my initial outlook on the future was grim. My cynicism was compounded by a feeling of helplessness stemming from our country's inability to achieve major political change. Slowly, however, I am embracing the major imperative-revolutionary change is inevitable. Our system must be completely rebuilt, not just remodeled. And we do not need more resources. The necessary bricks and mortar are available.

For a while, incremental changes may continue to patch broken bricks and fill cracks with putty, and major political battles will be further postponed. But these measures are only temporary and are often not directed toward doing what is best for patients. The system requires major renovations, and we need a blueprint for change. The primary care community must lead this change. Some stand to gain, others will lose, but the process of rebuilding has got to get started. I suggest one model to ponder.

\section{A BLUEPRINT FOR CHANGE}

For the foundation, the federal government could provide reimbursement and/or direct delivery of preventive services for all people. (This foundation might also include some evidence-based primary and chronic care services.) The basket of services supported by this provision would be determined by recommendations from objective national bodies such as the US Preventive Services Task Force, after extensive evidence reviews. This foundational layer would be sufficiently elastic to allow for continued deliberation and easy modification, as evidence frequently changes.

Critics of this proposed approach would likely cite high costs and limited accessibility of treatment services. The costs involved in maintaining this strong foundation would actually be fairly predictable based on the demographic characteristics of the population. Beyond these initial costs, the universal delivery of preventive services would encounter resistance because patients might discover they have a disease but not have the financial means to obtain treatment. This potential obstacle has stalled more-widespread provisions for preventive screening in the current system. I believe the more humane approach would be a new system designed to ensure universal availability of evidence-based treatments rather than to deny screening.

Next, and closely linked with preventive services, is primary care. The delivery of primary care services is currently under major renovation with the redesign of practices and the infusion of new technologies that streamline the process and facilitate greater patient participation. ${ }^{13}$ The diminishing role of insurance payment for basic primary care services suggests that this mechanism of reimbursement may not survive into the future. These innovative approaches must, therefore, also be designed to sustain the potential (inevitable?) collapse of Medicare, Medicaid, and the employersponsored insurance model. Financing for these ser- 
vices might blend models used in capitated retainer practices, FQHCs, managed care organizations, and direct self-pay arrangements. Above all, innovations in primary care must focus on improving patient care by incorporating concepts of a medical home, continuity of care, evidence-based medicine, and shared patientclinician decision making.

Until preventive and primary care services are universal, it will be impossible to predict the demands for secondary and tertiary care. Nonetheless, secondary and tertiary services, as well as chronic disease management by primary care clinicians, are unaffordable to most Americans. Thus, the current participants will need to continue as purchasers and insurers of care in some form. Employers, private insurers, the federal government, consumer groups, provider groups, and others with vested interests must come to the table to redesign this portion of the delivery and financing structure.

The tools for rebuilding the secondary and tertiary care structures are available, but it will take brave and visionary leaders to use the tools. For example, the practical application of theoretical models-such as care-rationing schemes-may come with politically undesirable consequences that threaten campaign contributions, voter confidence, and political futures. These decisions, however, are already being made at state levels for Medicaid populations, by employersponsored health plans, and within such smaller systems as the Veterans Affairs hospitals and Kaiser Permanente. In the rebuilding process, these decisions need to be made nationally with the involvement of all vested participants. Furthermore, ground rules must be established to ensure equitable distribution of resources and to prevent leaving vulnerable populations behind. One example might be an individual mandate to purchase a regulated catastrophic insurance product (with public subsidies based on income) combined with a mechanism to eliminate current insurance practices to reject preexisting conditions.

I am sensitive to the huge amount of energy required to keep clinic doors open and to provide patient-centered services, and most family physicians should continue this essential endeavor. Some of the renewed energy to redesign primary care, however, must be harnessed and directed toward rebuilding the overall health care system. The major imperative is to rebuild a unified, sustainable delivery system with equitable and comprehensive financing, using a finite amount of resources (the existing bricks and mortar). Although guided by expert models and projections, this redesign process could easily be stalled by political impasse and refusals to redistribute available resources. The other alternative is to continue reshuffling bricks in the current system. Why keep reshuffling bricks in an unsustainable system that denies basic access to patients when efforts could be directed toward developing a blueprint and rebuilding a more equitable and sustainable system?

To read or post commentaries in response to this article, see it online at http://www.annfammed.org/cgi/content/full/6/3/263.

Key words: Delivery of health care; health policy; health care quality, access, and evaluation; access to health care; health care economics and organizations

Submitted July 3, 2007; submitted, revised, January 8, 2008; accepted January 21, 2008.

Acknowledgments: I am grateful to Robert Phillips, Jr, for the inspiration and many of the ideas discussed in this essay, and to John Saultz for his unwavering support in my quest to publish these ideas.

\section{References}

1. Kaiser Family Foundation. Trends in Health Care Costs and Spending. Menlo Park, CA: Kaiser Family Foundation. http://www.kff.org/ insurance/upload/7692.pdf. Accessed Dec 14, 2007.

2. DeVoe JE, Dodoo MS, Phillips RL, Green LA. Graham Center onepager: who will have health insurance in 2025. Am Fam Physician. 2005;72(10):1989.

3. May J, Cunningham P. Tough Trade-Offs: Medical Bills, Family Finances and Access to Care. Issue Brief No. 85. Washington DC: Center for Studying Health System Change; 2004.

4. Families USA. One in Three: Non-Elderly Americans without Health Insurance, 2002-2003. Washington DC: Families USA Foundation; 2004.

5. US Government Accountability Office. Budget Process: Long-Term Focus is Critical. Statement of David Walker Comptroller General of the United States in Testimony Before the Subcommittee on Legislative and Budget Process, Committee on Rules, US House of Representatives. http://www.gao.gov/new.items/d04585t.pdf. Accessed Oct 15, 2007.

6. Walker D. Comptroller General's Forum on Health Care: Unsustainable Trends Necessitate Comprehensive and Fundamental Reforms to Control Spending and Improve Value. GAO-04-793SP. May 1, 2004. http:// www.gao.gov/new.items/d04793sp.pdf. Accessed Oct 15, 2007.

7. Carlson M, DeVoe J, Wright B. Short-term impacts of coverage loss in a Medicaid population: early results from a prospective cohort study of the Oregon Health Plan. Ann Fam Med. 2006;4(4):391-398.

8. Hurley R. TennCare-A failure of politics, not policy: a conversation with Gordon Bonnyman. Health Affairs-Web Exclusive. 2006;25(3): w217-w225.

9. Weiss E, Haslanger J, Cantor J. Accessibility of primary care services in safety net clinics in New York City. Am J Public Health. 2001;91(8):1240-1245.

10. Proser M, Shin P, Hawkins D. A Nation's Health At Risk III: Growing Uninsured, Budget Cutbacks Challenge President's Initiative to Put a Health Center in Every Poor County. Washington DC: National Association of Community Health Centers and The George Washington University; 2005.

11. Altman S, Shactman D, Eilat E. Could U.S. Hospitals go the Way of U.S. Airlines? Health Aff. 2006;25(1):11-21.

12. Wilkinson R, Marmot M, eds. Social Determinants of Health: The Solid Facts. Geneva, Switzerland: The World Health Organization; 1998.

13. Martin JC, Avant RF, Bowman MA, et al. The future of family medicine: a collaborative project of the family medicine community. Ann Fam Med. 2004;2(Suppl 1):S3-S32. 